\section{Scope of Human Frontiers}

SIR - As a member of the Council of Scientists of the Human Frontier Science Program (HFSP) since the programme was launched three years ago, I appreciate the recent discussion in Nature about an issue crucial to the programme and its future, namely its scientific scope. I have always strongly supported the original intention behind the programme, expressed by Dr Akiyoshi Wada (Nature 357, 356; 1992) and endorsed editorially (358, 525 \& $527 ; 1992)$, that the broad interdisciplinarity of the HFSP is exactly what makes the programme a frontier science programme. Take that away and the programme is reduced to a traditional, albeit international, funding agency for the biological sciences. There are two important questions that seem to have been left hanging in the air.

First, although not at all surprising to insiders, it is a matter of real concern that Dr Edward Rall (present chairman of the Council of Scientists), Dr Joseph Varner (former member of the Council of Scientists) and Sir James Gowans (retiring Secretary-General of the Human Frontier Science Program Organization) apparently agree on an important point of immediate and potentially serious practical consequence. They apparently all think that Wada's article in Nature has created confusion among the applicants in the next round of applications for the HFSP for which the closing date is the end of September 1992. Their position amounts to (1) a warning to potential applicants that they should not submit proposals to the HFSP that fit Wada's description of the broad interdisciplinarity of the programme and (2) a flat denial of the broad interdisciplinarity of the programme itself.

I should like to emphasize that Wada has not created any confusion among potential applicants. His presentation of the scope of the programme agrees exactly with the published information on the programme, including all published information to potential applicants. Wada has merely, and in my view correctly, drawn attention to the fact that the HFSP is a truly interdisciplinary scientific programme whose scope includes the many disciplines that currently collaborate with the biological sciences to elucidate the functions and mechanics of living organisms, such as physics, chemistry, engineering, the cognitive sciences and the study of behaviour as caused by information-processing. I recommend therefore that potential applicants to the HFSP should not refrain from submitting truly interdisciplinary research proposals that fit the published description of the programme's scope.
My second point is simple and has in effect already been made. The issue over the broad interdisciplinarity of the $\mathrm{Hu}$ man Frontier Science Program is not an issue of "Japan against the rest of the world": it is an issue between those who wish to maintain the HFSP's hallmark as a true frontier science programme and those who do not.

Niels Ole Bernsen

Centre of Cognitive Science,

Roskilde University,

PO Box 260,

DK-4000 Roskilde, Denmark

\section{Occupational risks}

SIR - Attractive though they are, the technical properties of ultra-thin manmade fibres pointed out by Paul Calvert (Nature 357, 365; 1992) should not hide the potential - at least for those fibres resistant to biological degradation in vivo - for related occupational risks to workers.

Fortunately, most reinforcing fibres hitherto produced in quantity have, as Calvert pointed out, been of diameter 10 $\mu \mathrm{m}$ or more; the practical risk from occupational or other exposure to their airborne dusts remains doubtful. But work on fibres other than asbestos has shown the morphology and biological persistence of fibrous materials to be of greater significance in relation both to pneumoconiosis and, more seriously, to mesothelioma, than their chemical constitution.

A need for stringent precautions in preventing occupational exposure to the dusts of these thinner materials might well result in cost increases in manufacture that would outweigh the "dramatic reduction in production costs" hypothesized by Calvert.

Gerald V. Coles

Occupational Hygiene Unit,

Deakin University,

Geelong, Victoria 3217, Australia

\section{Czech science}

SIR - I was disgusted by Dr Z. Vaněk's letter about the recent problems in Czechoslovak science (Nature 357, 10; 1992). His allegations that the newly introduced granting system in the institutes of the Academy of Sciences is based on "family favours" made me really furious. There are many problems in our science, but the introduction of an internal granting system by the academy was clearly the most positive achievement of the past two years. This was the first attempt in our country to lay new foundations for selective funding of good projects.

It is not the fault of the academy that it has not yet been possible to create a more general granting agency to fund research outside the academy. The academy's internal granting agency began to operate last year on the anonymous peer review principle; scientific and administrative bodies of the agency were democratically elected by the scientific community. About 40 per cent of all applicants were given grants. I would like to point out that there have been truly deep democratic reforms in the Czechoslovak Academy of Sciences since 1989 ; to my taste the present system is perhaps too democratic. I say this even though I am just an ordinary scientist, not a member of any academy or granting agency bodies. Clearly Vaněk did not get a grant for his project.

Similarly untrue is Vaněk's statement that existing institutes are being forced to split into smaller institutes in order to create more posts for directors. This has not happened, although many scientists believe that some large and heterogeneous institutes could perhaps be divided into smaller and more efficient independent units. I can assure you that at present few people would like to be a director. Vaněk's attacks on independent international boards that should evaluate the efficiency of the institutes is characteristic of those who are afraid of the results of such evaluation. Finally, I would like to express my disappointment that you failed to check the real state of affairs before publishing Vaněk's claims. Václav Hořejší

Institute of Molecular Genetics,

Czechoslovak Academy of Sciences,

Vídeňská 1083 ,

14220 Praha 4, Czechoslovakia

\section{Vaccine errors}

SIR - There are several errors in your news story about the Sclavo Research Institute (Nature 357, 6; 1992). In the last paragraph, Haemophilus influenzae $\mathrm{b}$ is referred to as a virus, when it is in fact a bacterium. Second, what is described as "a vaccine against recombinant pertussis toxin" is actually a vaccine consisting of a recombinant pertussis toxin.

Furthermore, many would take issue with the "association with neurological damage" of the "current whooping cough vaccine". Lastly, the bacterium Helicobacter pylori is misspelled.

Janet R. Gilsdorf

Carl F. Marrs

University of Michigan Medical Center,

C. S. Mott Children's Hospital, 1500 E. Medical Center Drive,

Ann Arbor, Michigan 48109-0244, USA 